\title{
PELATIHAN PENGOLAHAN KULIT MELINJO SEBAGAI CAMILAN SEHAT UNTUK PENINGKATAN PENDAPATAN KWT SEJAHTERA DUSUN KEPUH KULON DESA WIROKERTEN
}

\author{
Anis Febri Nilansari ${ }^{1, *}$, Setia Wardani ${ }^{2}$ \\ ${ }^{1}$ Program Studi Farmasi, Universitas PGRI Yogyakarta \\ ${ }^{2}$ Program Studi Informatika, Universitas PGRI Yogyakarta \\ Email Korespondensi: *anis@upy.ac.id
}

Received : July $2^{\text {nd }}, 2020$; Accepted : August 14, 2020 ; Published : January $1^{\text {st }}, 2021$

\begin{abstract}
Abstrak
Mitra pada Pengabdian kepada Masyarakat (PkM) ini adalah Kelompok Wanita Tani (KWT) Sejahtera yang bergerak pada bidang pertanian, berlokasi di Dusun Kepuh Kulon Desa Wirokerten berjarak 10,7 km dari Universitas PGRI Yogyakarta (UPY). Masalah utama pada mitra adalah melimpahnya sisa hasil produksi dari KWT Sejahtera berupa kulit melinjo yang belum dikelola dan dimanfaatkan oleh anggota dan masyarakat untuk menambah pendapatan keluarga karena belum adanya pendampingan tentang pengolahan makanan ringan, jangkauan pasar masih lokal dan desain serta pengemasan produk yang masih konvensional. Tujuan PkM menumbuhkan kesadaran anggota KWT Sejahtera Dusun Kepuh Kulon Desa Wirokerten dalam pemanfaatan kulit melinjo, memberikan pengalaman dan pengetahuan tentang pengolahan kulit melinjo, penentuan harga camilan kulit melinjo dan pengemasan produk serta penjualan produk berbantuan media sosial. Solusi untuk mengatasi masalah yang ada pada mitra yaitu dengan metode penyuluhan dan pelatihan diantaranya (1) Penyuluhan dan pelatihan pengolahan kulit melinjo, (2) Pelatihan pengemasan produk, (3) Pelatihan manajemen pemasaran produk dengan memanfaatkan media sosial. Hasil dari PkM ini adalah kripik kulit melinjo yang telah dikemas, promosi produk dengan memanfaatkan media sosial serta artikel yang dipublikasikan pada jurnal pengabdian masyarakat.
\end{abstract}

Kata Kunci : KWT Sejahtera, kulit melinjo, Wirokerten dan sosial media.

\begin{abstract}
The partner on Community Devotion (PkM) is a group of farmer Women (KWT) Sejahtera who is engaged in agriculture, located in the hamlet of Dusun Kepuh Kulon Desa Wirokerten is $10.7 \mathrm{~km}$ from PGRI Yogyakarta University (UPY). The main problem with the partners is the abundance of residual products from KWT Sejahtera, which is a skin that has not been managed and utilized by members and communities to increase family income because there is no assistance on the processing of snacks, local market reach and the design and packaging of the products are still conventional. The purpose of PkM raised the awareness of KWT Sejahtera Dusun Kepuh Kulon Desa Wirokerten in the use of Melinjo skin, providing experience and knowledge of Melinjo skin treatment, the price determination of Melinjo skin and product packaging as well as sales of social media-assisted products. Solutions to address the problems that exist in the partner is by counseling and training methods such as (1) Counseling and skin treatment training Melinjo, (2) Training on product packaging, (3) Product marketing management training by utilizing social media. The results of this PkM are Melinjo skin chips that have been packaged, the promotion of products by utilizing social media as well as articles published on the Journal of Community Devotion.
\end{abstract}

Keywords: KWT Sejahtera, Melinjo skin, Wirokerten and social media. 


\section{Latar Belakang Masalah}

Desa Wirokerten secara geografis masuk dalam Kecamatan Banguntapan, dengan jarak sekitar 10,7 km dari Universitas PGRI Yogyakarta. Dari jumlah keseluruhan penduduk di Kecamatan Banguntapan, sebagian besar penduduknya bermata pencaharian petani, dari data monografi Kecamatan Banguntapan tercatat 17.869 orang atau 23,39\% penduduk Kecamatan Banguntapan bermata pencaharian sebagai petani, selain itu penduduk di Kecamatan Banguntapan juga mengandalkan sentra industri sebagai mata pencahariannya.

Perkembangan sektor industri dalam pembangunan di Indonesia tidak terlepas dari peranan dan keberadaan industri kecil [1]. Di Uganda, UMKM memainkan peran penting dalam menciptakan peluang kerja yang memungkinkan tercapainya pertumbuhan dan pembangunan yang adil dan berkelanjutan[2]. Usaha Mikro Kecil Menengah (UMKM) umumnya dianggap sebagai penggerak pertumbuhan ekonomi dan pemerataan pembangunan dalam suatu negara berkembang[3], dimana UMKM mempunyai peranan dalam mengurangi mengurangi pengangguran dan kemiskinan khususnya untuk negara-negara berkembang[4] serta persaingan regional, nasional, maupun internasional perlu ditingkatkan kualitas dan kapasitas produksi[5] dan dibutuhkan komitmen, kemauan yang kuat dalam meningkatkan produktifitas UMKM. Sifat operasi, kinerja, struktur aset, kewajiban, modal, peluang pendanaan, perekrutan karyawan, pelatihan, kualifikasi mereka dan banyak elemen lain yang pada dasarnya berbeda dari yang dimiliki perusahaan besar[6], akan tetapi jaringan adalah cara yang berguna bagi pemilik UMKM untuk memperluas keahlian pemasaran dan meningkatkan kinerja[7]. Jaringan bisnis mengacu pada asosiasi bisnis gratis, yang mampu menciptakan struktur dan proses, pengambilan keputusan bersama dan mengintegrasikan upaya anggota untuk merancang dan memproduksi barang dan jasa, dan bertukar informasi dan sumber daya lainnya[8]. Jaringan dalam UKM mengacu pada proses jaringan yang dilakukan oleh pemilik UMKM dalam mengelola kegiatan bisnis[9].

Desa Wirokerten tepatnya Dusun Kepuh Kulon memiliki UMKM sentra makanan tradisional emping melinjo yang dikelola oleh warganya sejak tahun 2009. Sentra Emping Mlinjo yang ada di Dusun Kepuh Kulon Desa Wirokerten ini merupakan usaha home industri yang dikelola oleh Kelompok Wanita Tani (KWT) Sejahtera, salah satunya sebagai pendukung Badan Usaha Milik Desa (BUMDES) Wirajaya Makmur dan sebagai penunjang kesejahteraan masyarakat di bidang perekonomian.

Melinjo memiliki bagian berupa biji dan kulit, di berbagai daerah, biji melinjo banyak dibuat produk berupa emping melinjo. Biji melinjo memiliki kandungan purin yang tinggi menyebabkan terjadinya asam urat, sedangkan kulit melinjo yang saat ini belum banyak diolah memiliki kandungan flavonoid, saponin, alkaloid dan polifenol yang bermanfaat dalam mencegah terjadinya penyakit asam urat yang seringkali mendera.

Pada saat ini kelompok usaha KWT Sejahtera tepatnya berlokasi di Dusun Kepuh Kulon mempunyai produk utama berupa emping melinjo. Produk tersebut berbahan baku utama biji melinjo, sedangkan kulitnya belum banyak dimanfaatkan. Kulit melinjo selama ini hanya dijual dalam bentuk mentahan atau kiloan dipasar untuk dibuat bahan sayur kulit melinjo, bahkan kulit hanya dijadikan pupuk atau dibuang. Berdasarkan observasi tim pengabdi dan hasil diskusi dengan Kepala Dusun (Dukuh) Kepuh Kulon dibutuhkan usaha pemberdayaan masyarakat berupa pemanfaatan kulit melinjo menjadi produk olahan yang dapat dijual atau memiliki nilai jual sehingga dapat mendukung perekonomian anggota KWT Sejahtera Dusun Kepuh Kulon Desa Wirokerten. Hal ini seiring dengan tujuan dari Pengabdian Pada Masyarakat (PPM) yang diantaranya (a) menumbuhkan pemahaman masyarakat Kelompok Usaha Emping Melinjo Desa Wirokerten tentang manfaat kulit 
melinjo bagi Kesehatan, (b) menumbuhkan kesadaran masyarakat Kelompok Usaha Emping Melinjo Desa Wirokerten untuk memanfaatkan kulit melinjo menjadi camilan yang bernilai jual tinggi, (c) menumbuhkan keterampilan masyarakat KWT Sejahtera Dusun Kepuh Kulon Desa Wirokerten untuk mengolah kulit melinjo menjadi camilan yang bernilai jual tinggi. Olahan kulit melinjo dapat menjadi alternatif camilan sehat sebagai pengganti camilan yang saat ini beredar, karena banyak mengalami proses pengolahan dan mengandung penyedap rasa yang tidak memiliki nilai gizi dan manfaat bagi tubuh. Pemberdayaan masyarakat Dusun Kepuh Kulon Desa Wirokerten membutuhkan kesadaran warga untuk memanfaatkan kulit melinjo menjadi produk olahan yang dapat memiliki nilai jual, sehingga pada pelatihan pengolahan kulit melinjo KWT Sejahtera Kepuh Kulon Desa Wirokerten dimulai dengan penyuluhan sebagai upaya penguatan Sumber Daya Manusia (anggota KWT Sejahtera) dan dilanjutkan pelatihan pengolahan kulit melinjo sampai pada tahap pengemasan yang menarik dan penjualan dengan memanfaatkan sosial media, sedangkan manfaat dari PPM antara lain (a) membuka lapangan kerja baru bagi masyarakat Dusun Kepuh Kulon, (b) meningkatkan keterampilan anggota KWT Sejahtera dalam hal peningkatan kualitas produk yang dihasilkan, pengemasan dan pemanfatan social media untuk promosi usahanya.

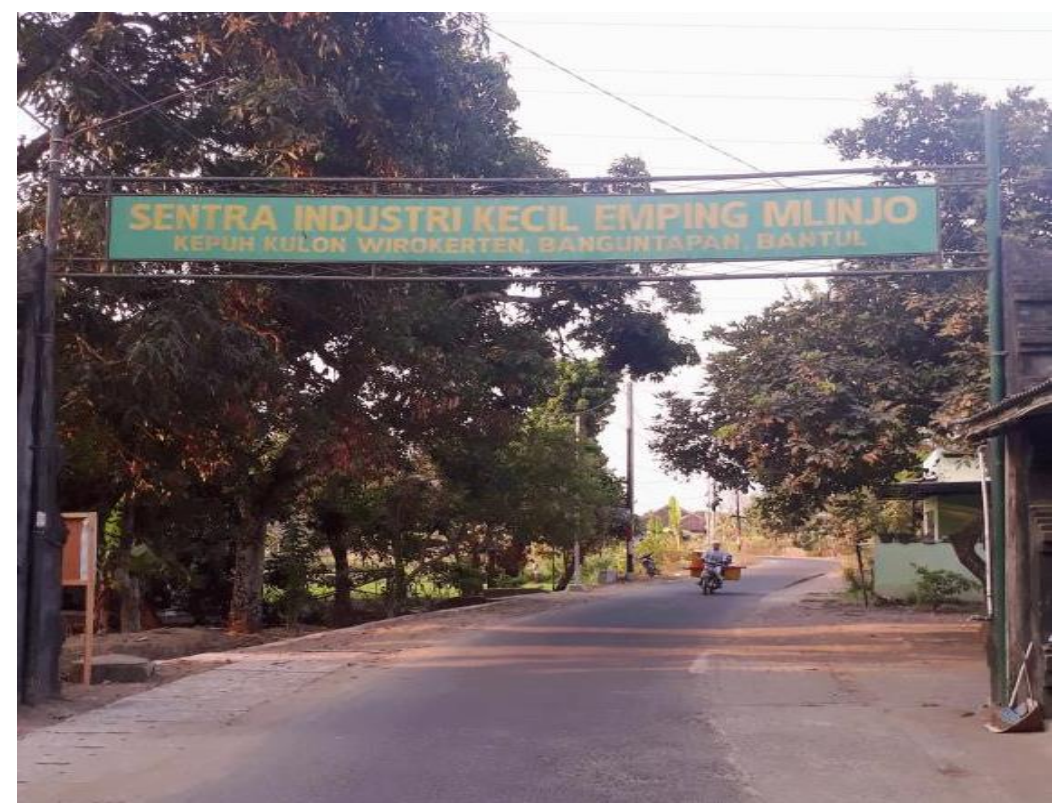

Gambar 1. Gerbang sentra Emping Melinjo

\section{Metode}

Metode yang digunakan pada pengabdian masyarakat ini adalah $25 \%$ untuk ceramah, $50 \%$ untuk praktek, dan $25 \%$ untuk tanya jawab. Penggunaan metode ini diharapkan dapat mempermudah seluruh peserta dalam memahami materi yang diberikan. Ceramah yang dilaksanakan pada pendopo Dusun Kepuh Kulon yang berhubungan dengan Sumber Daya Masyarakat (SDM), pengolahan produk dan pengemasan. Berbagai teori disampaikan kepada peserta agar mampu memberikan gambaran tentang SDM, pelatihan pengolahan produk dan pengemasan. Setiap peserta diberikan handout materi agar dapat memahami materi yang dijelaskan. Materi manfaat kulit melinjo juga disampaikan guna memberikan penjelasan kepada masayarakat mengenai kandungan gizi sehat yang terkandung dalam kulit melinjo. Setelah diberikan ceramah penguatan SDM untuk menumbuhkan kesadaran pemanfaatan kulit melinjo, kemudian dilanjutkan dengan materi pengolahan kulit melinjo dan pengemasan yang menarik serta pengalaman usaha dengan memanfaatkan media sosial. Untuk lebih rincinya lihat pada tabel 1 berikut ini. 
Tabel 1. Kegiatan dan langkah dalam pengabdian

\begin{tabular}{|c|c|c|}
\hline No & Kegiatan & Langkah-langkah \\
\hline \multicolumn{3}{|c|}{ Persiapan } \\
\hline 1 & Perijinan ke Padukuhan Kepuh Kulon & $\begin{array}{l}\text { a. Pembuatan permohonan surat ijin ke } \\
\text { LPPM untuk kegiatan Pengabdian } \\
\text { kepada Masyarakat. } \\
\text { b. Perijinan pada Padukuhan Kepuh } \\
\text { Kulon }\end{array}$ \\
\hline 2 & $\begin{array}{l}\text { Koordinasi mitra terkait kegiatan } \\
\text { Pengabdian kepada Masyarakat }\end{array}$ & $\begin{array}{l}\text { a. Menentuan lokasi kegiatan PPM } \\
\text { b. Menentukan waktu dan tanggal } \\
\text { pelaksanaan PPM }\end{array}$ \\
\hline \multicolumn{3}{|c|}{ Pelaksanaan } \\
\hline 1 & $\begin{array}{l}\text { Penyuluhan Manfaat kulit melinjo untuk } \\
\text { Kesehatan } \\
\text { Dilaksanakan pada hari minggu tanggal } 21 \\
\text { juni } 2020\end{array}$ & $\begin{array}{l}\text { a. Penyuluhan manfaat kulit melinjo } \\
\text { bagi kesehatan } \\
\text { b. Penyuluhan manfaat kuit melinjo } \\
\text { sebagai produk camilan }\end{array}$ \\
\hline 2 & $\begin{array}{l}\text { Penyuluhan dan pelatihan promosi melalui } \\
\text { sosial media dan pengemasan produk yang } \\
\text { menarik } \\
\text { Dilaksanakan pada hari senin tanggal } 22 \\
\text { juni } 2020\end{array}$ & $\begin{array}{l}\text { a. Pelatihan promosi melalui sosial } \\
\text { media } \\
\text { b. Pelatihan dan praktik pengemasan } \\
\text { produk } \\
\text { c. Pelatihan pembbuatan desain produk }\end{array}$ \\
\hline 3 & $\begin{array}{l}\text { Pengelolaan kulit melinjo menjadi camilan } \\
\text { bernilai jual tinggi } \\
\text { Dilaksanakan pada hari selasa tanggal } 23 \\
\text { juni } 2020\end{array}$ & $\begin{array}{l}\text { a. Pelatihan pemberian harga jual } \\
\text { untuk produk } \\
\text { b. Pelatihan pemilihan bahan baku dari } \\
\text { produk } \\
\text { c. Pendampingan dan evaluasi }\end{array}$ \\
\hline
\end{tabular}

\section{Hasil dan Pembahasan}

Kegiatan Pelatihan Pengolahan Kulit Melinjo Sebagai Camilan Sehat Untuk Peningkatan Pendapatan KWT Sejahtera Dusun Kepuh Kulon Desa Wirokerten berlangsung selama 3 hari yaitu pada tanggal 21 Juni 2020, 22 Juni 2020, dan 23 Juni 2020 mulai pukul 09.00 - 12.00 WIB. Kegiatan Pengabdian Kepada Masyarakat ini berlangsung pada saat masa pandemi covid-19, namun untuk melaksakan tugas dan tanggungjawan dosen yaitu Tri Dharma Perguruan Tinggi berupa Pendidikan, Penelitian dan Pengabdian, oleh karena itu pengabdian tetap dijalankan. Pengabdian Kepada Masyarakat ini berlangsung degan menerapakan protokol kesehatan berupa wajib memakai masker, cuci tangan sebelum mengikuti penyuluhan dan pengolahan, jaga jarak dan menghindari kontak fisik. Peserta yang hadir pada hari pertama berjumlah 35 orang, yaitu ibu-ibu anggota KWT Sejahtera Dusun Kepuh Kulon Desa Wirokerten.

Sebelum dilakukan pengabidan kepada masyarakat, dilakukan analisis situasi kondisi mitra dengan melakukan wawancara terhadap Ketua Dukuh Kepuh Kulon. Hasil wawancara berupa analisis SWOT yang dapat membantu dalam penentuan jalannya pengabidan kepada masyarakat. Tabel 2. merupakan analisis SWOT dari KWT Sejahtera Dusun Kepuh Kulon Desa Wirokerten. 
Tabel 2. Analisis SWOT KWT Sejahtera Dusun Kepuh Kulon Desa Wirokerten

\begin{tabular}{|c|c|c|}
\hline & Strength $(S)$ & Weakness (S) \\
\hline $\begin{array}{c}\text { Faktor-fakto } \\
\text { Eksternal }\end{array}$ & $\begin{array}{l}\text { Kelompok usaha } \\
\text { sudah memiliki ijin } \\
\text { usaha dan memiliki } \\
\text { bahan utama berupa } \\
\text { kulit melinjo yang } \\
\text { siap untuk diolah. } \\
\text { Emping melinjo } \\
\text { sebagai pekerjaan } \\
\text { utama/ pokok warga } \\
\text { Desa Wirokerten. }\end{array}$ & $\begin{array}{l}\text { Kurangnya kesadaran } \\
\text { dan kemampuan dalam } \\
\text { hal pengemasan yang } \\
\text { menarik dan promosi. } \\
\text { Keterbatasan } \\
\text { keterampilan untuk } \\
\text { mengolah } \\
\text { melinjo kulit } \\
\text { camilan yang bernilai } \\
\text { jual tinggi }\end{array}$ \\
\hline $\begin{array}{l}\text { Opportunity }(O) \\
\text { Menciptakan lapangan } \\
\text { kerja baru sehingga dapat } \\
\text { meningkatkan } \\
\text { perekonomian warga Desa } \\
\text { Wirokerten dengan } \\
\text { memanfaatkan kulit } \\
\text { melinjo menjadi produk } \\
\text { camilan yang bernilai jual. }\end{array}$ & $\begin{array}{l}\text { Stratesi SO } \\
\text { Menambah jenis usaha } \\
\text { lainnya di kelompok usaha } \\
\text { emping melinjo Desa } \\
\text { Wirokerten. }\end{array}$ & $\begin{array}{l}\text { Strategi WO } \\
\text { Penyuluhan dan pelatihan } \\
\text { pemanfaatan kulit meinjo } \\
\text { menjadi camilan yang } \\
\text { bernilai jual tinggi. }\end{array}$ \\
\hline $\begin{array}{l}\text { Threat }(T) \\
\text { - Persaingan pasar } \\
\text { dengan produk olahan } \\
\text { sejenis. } \\
\text { Adanya anggapan } \\
\text { masyarakat bahwa } \\
\text { seluruh bagian melinjo } \\
\text { menyebabkan asam } \\
\text { urat. } \\
\end{array}$ & $\begin{array}{l}\text { Strategi ST } \\
\text { Membuat camilan kulit } \\
\text { melinjo dengan berbagai } \\
\text { rasa dan disertai dengan } \\
\text { penyuluhan manfaat kulit } \\
\text { melinjo. }\end{array}$ & $\begin{array}{l}\text { Strategi WT } \\
\text { Pendampingan pembuatan } \\
\text { kemasan produk yang } \\
\text { menarik disertai dengan } \\
\text { pembuatan } \\
\text { sebagai media promosite } \\
\text { online. }\end{array}$ \\
\hline
\end{tabular}

Berdasarkan analisis SWOT, dilakukan pemilihan metode pelaksanaan PKM di Dusun Kepuh Kulon Desa Wirokerten yaitu dengan cara penyuluhan, pelatihan dan pendampingan pengolahan kulit melinjo menjadi campilan yang bernilai ekonomis tinggi. Pelatihan disertai dengan manajemen pemasaran produk dengan memanfaatkan TIK. Penerapan penyuluhan diawali dengan menentukan sarana dan prasaranan yang diperlukan dalam melakukan diversifikasi dari produk KWT yaitu berupa kulit melinjo, dilanjutkan dengan cara pengolahan dan pengemasan menjadi camilan yang memiliki nilai ekonomis tinggi. Pelatihan pemanfaatan TIK dimaksudkan agar jangkauan pemasaran dapat dilakukan secara luas sehingga produk dapat dikomersialisasikan secara lokal dan konvensional namun juga melalui media sosial. Peserta PkM adalah anggota KWT di Dusun Kepuh Kulon Desa Wirokerten, yang bertujuan memberikan keterampilan kepada anggota KWT tidak hanya bergerak dalam bidang pembuatan emping melinjo, namun juga memanfaatkan kulit melinjo menjadi produk camilan. Kegiatan PkM yang telah dilakukan antara lain sebagai berikut :

a. Penyuluhan manfaat Kulit melinjo

Pada hari pertama Pengabdian Kepada Masyarakat di Dusun Kepuh Kulon Desa Wirokerten ini dilaksanakan pada tanggal 21 Juni 2020 pukul 09.00-12.00 WIB. Dilakukan penyampaian materi berupa manfaat kulit melinjo dari segi kesehatan. 
Penyampaian materi dimulai dengan pemanfaatan melinjo. Pohon melinjo terdiri dari biji, kulit, daun dan kayu yang banyak dimanfaatkan masyarakat Indonesia. Biji melinjo banyak dimanfaatkan menjadi emping melinjo yang saat ini juga diprosuksi dan menjadi sentra emping melinjo di Dusun Kepuh Kulon. Disamping pemafaatan biji melinjo menjadi olahan camilan emping melinjo, namun emping melinjo dikenal masyarakat mengakibatkan tingginya kadar asam urat apabila dikonsumsi terlau banyak. Daun melinjo juga dimanfaatkan masyarakat luas dengan mengolah menjadi sayur daun melinjo, sedangkan kayu dari pohon melinjo juga banyak dimanfaatkan. Sementara itu kulit melinjo, di Dusun Kepuh Kulon Desa Wirokerten hanya dimanfaatkan menjadi olahan sayur kulit melinjo, bahkan hanya dijadikan pupuk ternak. Pemanfaatan kulit melinjo belum sepenuhnya dilakukan oleh masyarakat KWT Sejahtera Dusun Kepuh Kulon. Kulit melinjo belum banyak dimanfaatkan menjadi olahan, olehkarena masih banyak anggapan masyarakat bahwa kulit melinjo apabila dikonsumsi dapat menyebabkan kadar asam urat tinggi. Kandungan kimia yang terdapat pada biji dan daun melinjo yaitu saponin, flavonoid, dan tanin sedangkan kulit melinjo mengandung saponin dan flavonoid[10]. Flavonoid, saponin, dan tanin yang terkandung pada melinjo tersebut dapat berfungsi sebagai antibakteri. Ekstrak etanol kulit melinjo memiliki aktivitas sebagai inhibitor xantin oksidase[11]. Xantin oksidase memiliki peranan penting dalam proses pembentukan asam urat dengan mengkatalisis hipoxantin menjadi xantin kemudian asam urat, sedangkan kulit melinjo memiliki aktivitas dalam menghambat enzim xantin oksidase sehingga menurunkan kadar asam urat. Olehkarena itu pada hari pertama pada kegiatan PKM ini dilakukan penyuluhan terkait manfaat kulit melinjo bagi kesehatan sehingga masyarakat tidak lagi merasa khawatir apabila ingin mengkonsumsi kulit melinjo. Gambar 2. merupakan penyampaian materi pemanfaatan kulit melinjo dari segi kesehatan yang disampaikan pemateri kepada KWT Sejahtera Dusun Kepuh Kulon Desa Wirokerten dengan menerapkan protokol kesehatan agar tehindar dari covid-19.

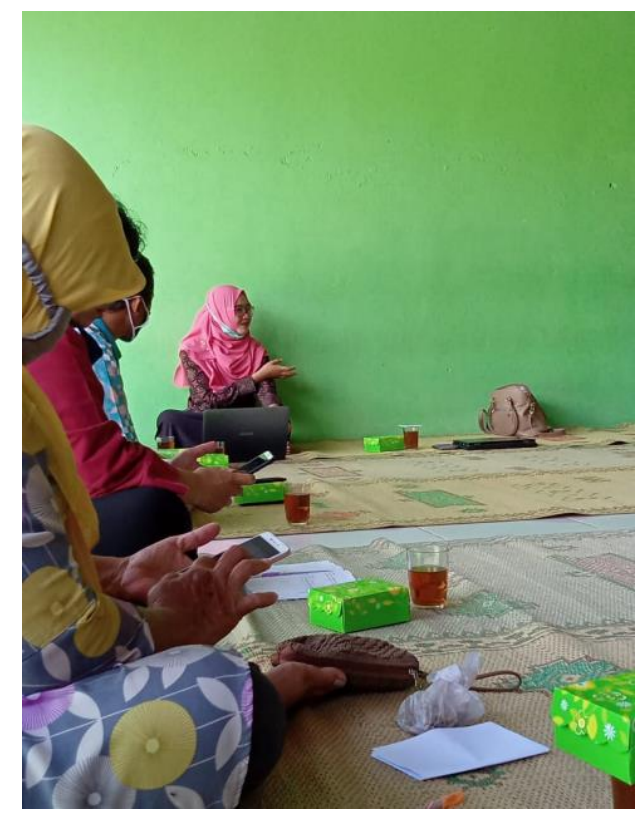

Gambar 2. Penyampaian Manfaat Kulit Melinjo

Materi penyuluhan manfaat kulit melinjo dilakukan dengan bantuan media elektronik berupa LCD agar mempermudah dalam penyampaikan materi. Materi yang disampaikan berupa power point. Penyampaian materi disertai dengan diskusi tanya jawab terkait manfaat kulit melinjo dari segi kesehatan. Diskusi memperlihatkan bahwa 
anggota KWT Sejahtera Dusun Kepuh Kulon Desa Wirokerten masih belum sepenuhnya mengetahui bahwa kulit melinjo memiliki nilai gizi yang tinggi dan bermanfaat untuk menurunkan kadar asam urat dalam tubuh.

b. Penyuluhan Promosi dan Pengemasan Produk

Pada hari kedua Pengabdian Kepada Masyarakat di Dusun Kepuh Kulon Desa Wirokerten ini dilaksanakan pada tanggal 22 Juni 2020 pukul 09.00-12.00 WIB. Dilaksanakan pemberian materi tentang promosi dan pengemasan produk. Materi ini merupakan kelanjutan dari materi yang pertama yaitu tentang manfaat kulit melinjo bagi kesehatan.

Penyuluhan tentang promosi dan pengemasan produk dilakukan di Pendopo Kepuh Kulon dengan dihadiri 32 warga KWT Sejahtera Kepuh Kulon Desa Wirokerten dengan menerapkan protokol kesehatan agar terhindar dari covid-19. Gambar 3. merupakan penyuluhan promosi dan pengemasan produk yang dilaksanakan di pendopo Dusun Kepuh Kulon.

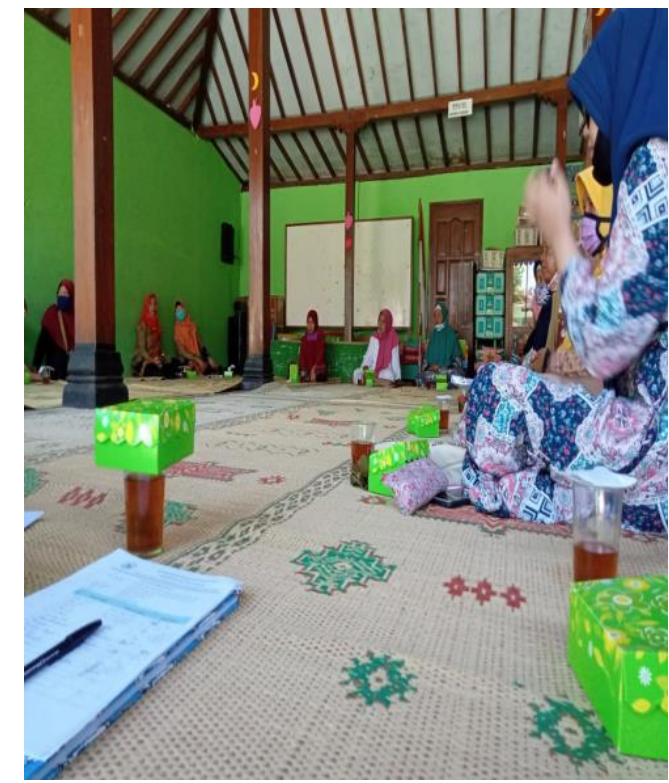

Gambar 3. Penyuluhan Promosi dan Pengemasan Produk

Penyampaian penyuluhan dilakukan dengan menggunakan alat bantu media elektronik yaitu LCD agar materi power point yang ditayangkan dapat tersampaikan dengan baik kepada peserta penyuluhan tersebut. Pemilihan materi berupa promosi dimaksudkan agar KWT Sejahtera Dusun Kepuh Kulon dapat memanfaatkan media sosial sebagai sarana dalam memperkenalkan produknya agar dapat dikenal masyarakat luas. Menurut data survei Kominfo pada tahun 2017 menunjukkan bahwa lebih dari setengah masyarakat Indonesia menggunakan telepon pintar atau smartphone dalam keidupan sehari-hari yaitu sebesar 66,3\% dan akan terus mengalami peningkatan setiap tahunnya. Rata-rata mereka menggunakan smartphone 3-5 jam perhari dalam aktivitasnya. Orang yang mengunakan smartphone tidak hanya usia dewasa, namun 50,79\% populasi usia 5065 tahun juga menggunakan smartphone[12]. Hal inilah yang melatar belakangi agar masyarakat dituntut dapat menggunakan teknologi untuk diambil manfaatnya yaitu salah satunya sebagai media dalam mempromosikan produk yang dijual.

Penyampaian materi tentang promosi diawali dengan manfaat sosial media dalam kehidupan sehari-hari, dilanjutkan dengan macam-macam media sosial yang dapat 
dimanfaatkan dalam promosi produk camilan kulit melinjo. Media sosial yang dapat digunakan KWT Sejahtera Dusun Kepuh Kulon dalam promosi produk camilan kulit melinjo yaitu dengan menggunakan Whatsapp, instagram dan website. Pada kesempatan ini kita juga mendatangkan wirausahawan yang sudah bergerak dalam bisnis produk makanan yang menjual dengan media online. Hal ini sebagai upaya agar peserta dapat langsung berinteraksi dan dapat melakukan diskusi terkait promosi yang dilakukan.

Setelah dilakukan penyampaian materi berupa promosi produk camilan kulit melinjo dengan media online, selanjutnya dilakukan penyampaian materi tentang pengemasan produk. Kemasan yang menarik akan menjadi daya tarik tersendiri bagi konsumen yang ingin membeli produk. Materi pengemasan produk dilakukan pada hari kedua ini untuk memberikan gambaran kepada KWT Sejahtera Dusun Keph Kulon dalam mengemas produk yang dapat menjadikan produk bernilai jual tinggi. Dalam kesempatan ini, pemateri memberikna contoh terkait produk camilan kulit melinjo yang sudah dikemas menggunakan plastik klip disertai dengan label produk. Gambar 4. merupakan contoh produk camilan kulit melinjo yang sudah dikemas dan dapat bernilai jual tinggi.

Pemberian contoh pengemasan produk dilakukan denagn memberikan contoh label dalam produk. Label produk memuat hal-hal yang berkaitan dengan produk seperti komposisi, rasa, tanggal expired date, nomer yang bisa dihubungi untuk memesan dan nama camilan kulit melinjo.

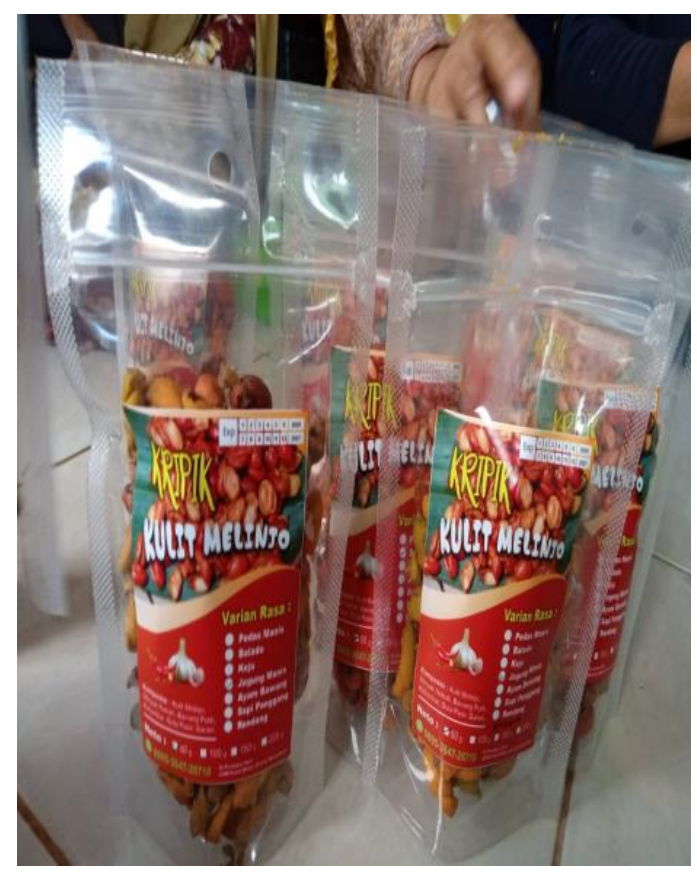

Gambar 4. Produk Camilan Kulit Menjo

\section{c. Pelatihan Pembuatan Camilan Kulit Melinjo}

Hari ketiga pelaksanaan Pengabdian Kepada Masyarakat dilakukan pelatihan pembuatan camilan kulit melinjo. Pelatihan ini dilaksanakan di pendopo Dusun Kepuh Kulon dengan dihadiri 36 peserta dari KWT Sejahtera Dusun Kepuh Kulon Desa Wirokerten. Sebelum pelatihan dilaksanakan, dipersiapkan terlebih dahulu alat dan bahan yang dibutuhkan. Alat yang dibutuhkan diantaranya ialah kompor, wajan, piring, sendok, serok. Sedangkan bahan yang dibutuhkan ialah kulit melinjo, minyak, penyedap rasa, cabai, dan gula. 
Pada pelatihan yang sudah berlangsung tersebut, terlihat bahwa peserta antusias untuk mengikuti pelatihan dengan ditandai bahwa peserta aktif ikut serta dalam pembuatan camilan kulit melinjo. Gambar 5. merupakan proses pembuatan camilan kulit melinjo yang dilakukan ibu-ibu KWT Sejahtera Dusun Kepuh Kulon.

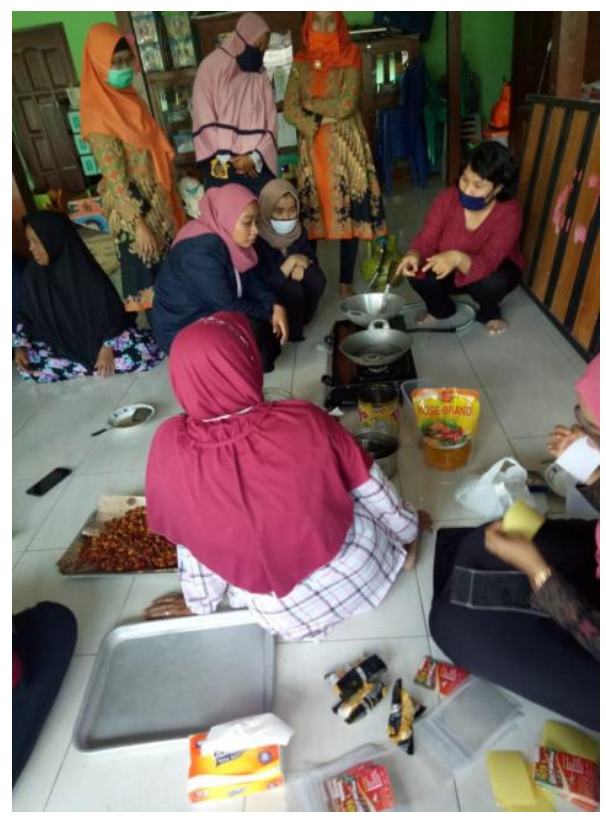

Gambar 5. Pelatihan Pembuatan Camilan Kulit Melinjo

Camilan kulit melinjo yang sudah jadi selanjutnya dilakukan pengemasan dan dilanjutkan penyampaian materi tentang strategi penentuan harga produk. Kulit melinjo yang sudah diolah menjadi camilan akan mengalami kenaikan harga dan berpotensi untuk dijual agar meningkatkan pendapatan bagi anggota KWT Sejahtera Dusun Kepuh Kulon. Pemanfaatan pengolahan kulit melinjo yang awalnya hanya dijadikan bahan olahan sayur kulit melinjo dan dijadikan untuk makan ternak, dengan adanya pelatihan ini diharapkan peserta dapat mengolahnya menjadi camilan kulit melinjo yang bernilai jual tinggi.

\section{Kesimpulan}

Dusun Kepuh Kulon Desa Wirokerten mempunyai potensi hasil produk yang sangat melimpah dimana KWT Sejahtera adalah sebagai kelompok pertanian yang mengelola usaha pertanian masyarakat diantaranya emping melinjo. Seiring berjalannya waktu KWT Sejahtera Dusun Kepuh Kulon mendapatkan berbagai masalah diantaranya adalah melimpahnya hasil produksi dari emping melinjo yaitu kulit melinjo, hal ini mengakibatkan hasil pertanian tersebut hanya dijadikan makanan ternak. Dari Permasalahan tersebut pelaksanaan PkM di Dusun Kepuh Kulon yaitu dengan mengadakan penyuluhan, pelatihan dan pendampingan pengolahan Sumber Daya Alam (SDA) lokal berupa hasil produksi (kulit melinjo) menjadi olahan yang bernilai ekonomis tinggi disertai dengan manajemen pemasaran produk dengan pemanfaatan sosial media. Dari hasil PkM ini kulit melinjo yang sebelumnya mempunyai nilai ekonomis renda dapat menjadi produk bernilai ekonomis tinggi yaitu berupa keripik kulit melinjo. Selain bernilai ekonomis tinggi kulit melinjo yang telah diolah menjadi lebih awet dan tahan lama.

\section{Daftar Pustaka}

[1] M. S. Cahyono, M. A. Sukrajap, and D. H. Harahap, "Penerapan Teknologi Produksi Makanan Olahan Untuk Pengembangan Usaha Kecil Dan Menengah Di Kota Bandung," Kacanegara, vol. 3, no. 1, pp. 21-30, 2020. 
[2] T. Peter and I. M. Cathy, "Networking for SMES in Uganda: A conceptual paper," African J. Bus. Manag., vol. 9, no. 2, pp. 43-49, 2015.

[3] D. J. Storey, Understanding the Small Business Sector. Thomson Learning, 1994.

[4] H. Hassan, A. Tretiakov, D. Whiddett, and I. Adon, "Extent of E-procurement Use in SMEs: A Descriptive Study," Procedia - Soc. Behav. Sci., vol. 164, no. August, pp. 264-270, 2014.

[5] R. Nurdin, "Peningkatan Kapasitas Produksi Usaha Wedang Uwuh Wonokromo Pleret Bantul Yogyakarta," Kacanegara, vol. 2, no. 1, pp. 7-12, 2019.

[6] L. Koçiu, R. Çelo, and R. Mano, "The role of risk culture in SMEs who operate in the Gjirokastra region,” Eur. Sci. J., vol. 11, no. 34, pp. 159-168, 2015.

[7] B. Kenny and J. Fahy, "SMEs' Networking Capability and International Performance," Adv. Bus. Mark. Purch., vol. 17, pp. 199-376, Aug. 2011.

[8] R. Trequattrini, giuseppe russo, and R. Lombardi, "Defining Business Network," Int. J. Bus. Res. Manag., vol. 3, pp. 29-34, Feb. 2012.

[9] H. Hakimpoor, T. Huam, N. Khani, and M. Bahrami, "Marketing networking dimensions (Mnds) and Smes' Performance: A new conceptual model," Aust. J. Basic Appl. Sci., vol. 5, pp. 1528-1533, Oct. 2011.

[10] C. Dewi and R. Utami, "Aktivitas Antioksidan dan Antimikroba Ekstrak Melinjo (Gnetum gnemon L)," vol. V, no. 2, pp. 74-81, 2012.

[11] Y. W. (Universitas N. Yogyakarta), "Upaya Pengembangan Pengrajin Batik Di Desa Wisata Batik," pp. 77-84.

[12] Kominfo, "Survey Penggunaan TIK serta Implikasinya terhadap Aspek Sosial Budaya Masyarakat," 2017. 